\title{
Easy cleaning of the scope's lens in a syringe to prevent condensation during laparoscopic surgery
}

\author{
Anne Jetteke Runia
}

Published online: 7 January 2010

(C) Springer Science+Business Media, LLC 2010

\section{Letter to the Editor}

Thank you for your comment on our simple method of prevention of lens fogging by using a syringe. The technique as described by Dr. Mohammadhosseini using povidone-iodine solution to clean the lens also can provide an inexpensive and simple method to prevent lens fogging. We curiously tested the method and would like to share our remarks.

Povidone-iodine does indeed provide a clear image. However, one should not apply too much iodine, because this gives a yellow image and one needs to swab it off, demanding some time. Being unable to use much iodine, one still has to apply the solution every several minutes to keep the image clear. This still leaves one with the problem of having to clean the lens often.
Iodine may be inexpensive; however, it is not cheaper than the lens cleaning solution (Anti-Fog, Purple Surgical, England) that we now use in our hospital. Furthermore, although rare, some people are allergic to povidone-iodine solution. Intra-abdominal application results in mucosal contact, which may provoke an allergic reaction, worse than application on the skin.

Concluding, the advantages of using povidone-iodine solution-namely inexpensive, readily available, and based on the soap principle-are hardly enough to persuade us to change methods in our clinic.

Disclosures Drs. Runia, Zengerink, and Mannaerts have no conflicts of interest or financial ties to disclose.

\footnotetext{
A. J. Runia ( $\bowtie)$

Department of Surgery, SFG, Rotterdam, The Netherlands

e-mail: jetteke@weaponofchoice.nl
} 